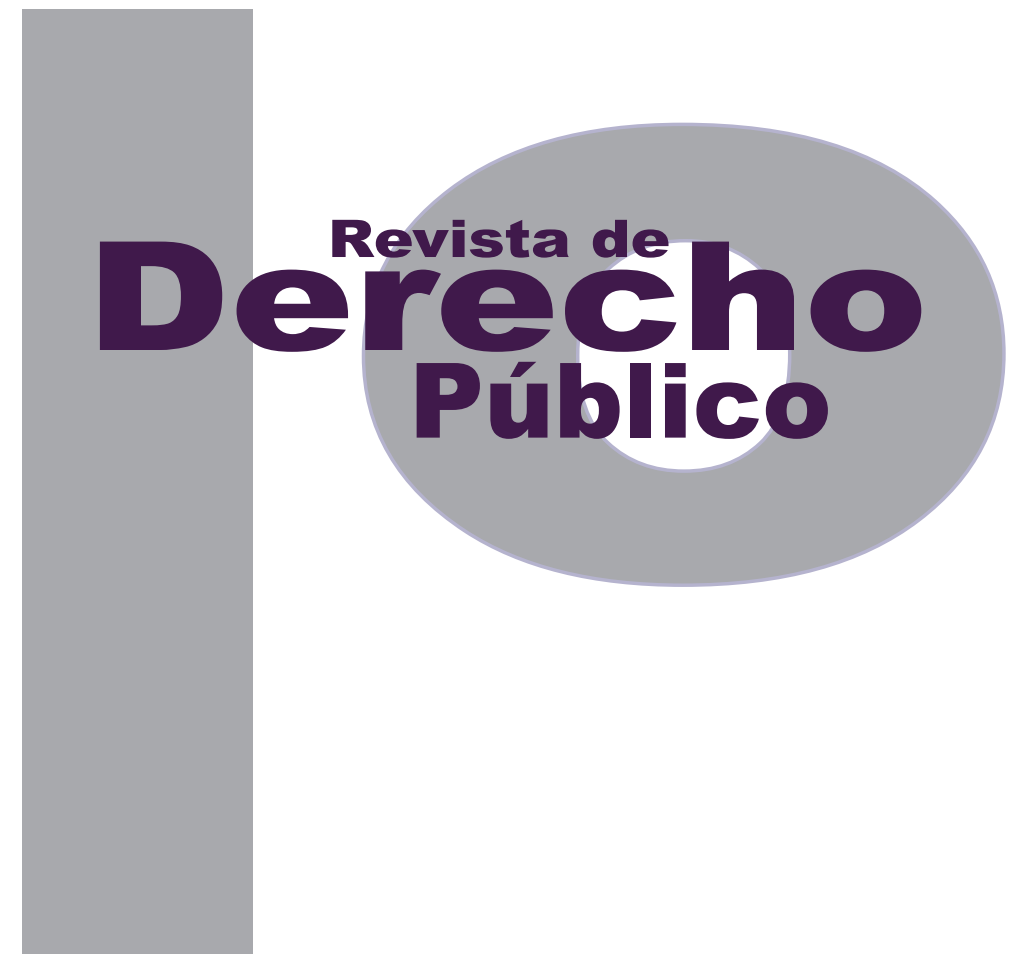

DEMOCRACIA, DESACUERDO Y DERECHO CONSTITUCIONAL. UNA REVISIÓN A LA TENSIÓN ENTRE CONSTITUCIONALISMO Y DEMOCRACIA EN EL DEBATE DWORKIN - WALDRON

\author{
SANTIAgo ViRgüEZ RUIZ
}

Artículo de reflexión

DOI: http://dx.doi.org/10.15425/redepub.35.2015.05

Universidad de los Andes

Facultad de Derecho

Rev. derecho publico No.35

julio - diciembre de 2015. ISSN 1909-7778 


\title{
Democracia, desacuerdo y derecho constitucional. Una revisión a la tensión entre constitucionalismo y democracia en el debate Dworkin - Waldron
}

\section{Resumen}

Este ensayo busca aterrizar las diversas tensiones existentes entre constitucionalismo y democracia al debate entre dos importante teóricos del derecho y la política: Jeremy Waldron y Ronald Dworkin. Mientras el primero sostiene que lo propio de la democracia es el desacuerdo, y por ello es inconveniente atrincherar derechos en constituciones inmodificables, el segundo argumenta que una concepción asociativa de la democracia, no meramente estadística, requiere la protección constitucional de ciertos derechos fundamentales como triunfos sobre las mayorías.

Una vez explicado el debate, se propone una defensa de un constitucionalismo acorde con la idea de democracia, a partir del reconocimiento de una cultura de los derechos como un hecho social compartido de la objetividad de los derechos fundamentales, y de la comprensión de la práctica constitucional como un espacio de deliberación representativa.

Palabras clave: constitucionalismo, desacuerdo, democracia asociativa, democracia procedimental, foro constitucional, control de constitucionalidad, cultura de los derechos.

\section{Democracy, disagreement and constitutional law. A review of the tension between constitutionalism and democracy in the Dworkin - Waldron debate}

\begin{abstract}
This essay seeks to ground the various tensions in the debate on constitutionalism and democracy between two important theorists of law and politics: Jeremy Waldron and Ronald Dworkin. While the former argues that democracy itself is disagreement, and therefore it is problematic to entrench laws in unchangeable constitutions, the second argues that an associative concept of democracy, not merely a statistical one, requires constitutional protection of certain fundamental rights that trump the majority.

Once this debate has been explained, the author proposes a defense of constitutionalism in line with the idea of democracy, based on the recognition of a culture of rights as a socially shared understanding of the true existence of fundamental rights and of the understanding of the practice of constitutional law as a space of representative deliberation.

Keywords: constitutionalism, disagreement, associative democracy, procedural democracy, constitutional forum, control of constitutionality, culture of rights.

\section{Democracia, desacordo e direito constitucional. Uma revisão da tensão entre constitucionalismo e democracia no debate Dworkin - Waldron}

\section{Resumo}

Este ensaio busca aterrissar as diversas tensões existentes entre constitucionalismo e democracia ao debate entre dois importantes teóricos do direito e da política: Jeremy Waldron e Ronald Dworkin. Enquanto o primeiro sustenta que o próprio da democracia é o desacordo, e por isso é inconveniente atrincheirar direitos em constituições imodificáveis, o segundo argumenta que uma concepção associativa da democracia, não meramente estatística, requer a proteção constitucional de certos direitos fundamentais como triunfos sobre as maiorias.

Uma vez explicado o debate, propõe-se uma defesa de um constitucionalismo de acordo com a ideia de democracia, a partir do reconhecimento de uma cultura dos direitos como um fato social compartilhado da objetividade dos direitos fundamentais, e da compreensão da prática constitucional como um espaço de deliberação representativa.

Palavras-chave: constitucionalismo, desacordo, democracia associativa, democracia procedimental, foro constitucional, controle de constitucionalidade, cultura dos direitos. 


\title{
Democracia, desacuerdo y derecho constitucional. Una revisión a la tensión entre constitucionalismo y democracia en el debate Dworkin - Waldron ${ }^{*}$
}

\author{
Santiago Virgüez Ruiz
}

\section{SUMARIO}

Introducción: democracia y constitucionalismo en tensión - I. EL DEBATE WALDRON - DWORKIN EN CONTEXTO: LÍNEAS PRINCIPALES DE DISCUSIÓN - A. ¿Son necesarias las cartas constitucionales de derechos? - B. ¿Son las constituciones y el control de constitucionalidad democráticos? - C. ¿Qué legitima la regla mayoritaria? El caso del "lifeboat" - II. DOS MODELOS DE DEMOCRACIA Y SU RELACIÓN CON EL CONSTITUCIONALISMO - A. El modelo democrático de mayorías. Un modelo procedimental - 1. El desacuerdo como fundamento de la concepción mayoritaria de democracia - 2. La votación como resultado natural del desacuerdo y la deliberación - 3. Constitucionalismo y democracia no van de la mano - B. El modelo asociativo de democracia. Un modelo sustantivo - 1. La dignidad y las condiciones de la democracia asociativa - 2. La condiciones democráticas y el constitucionalismo - III. ¿SE PUEDE HABLAR DE UN CARÁCTER DEMOCRÁTICO DEL CONSTITUCIONALISMO? - A. Al final, dos modelos de democracia sustantiva - B. Democracia, desacuerdo y constitucionalismo - 1. La cultura de los derechos como un hecho social compartido - 2. La objetividad de los derechos fundamentales (constitucionales) - 3. La práctica constitucional como un espacio de deliberación representativa - IV. CONCLUSIONES - Referencias.

Cómo citar este artículo: Virgüez Ruiz, S. (Diciembre, 2015). Democracia, desacuerdo y derecho constitucional. Una revisión a la tensión entre constitucionalismo y democracia en el debate Dworkin - Waldron. Revista de Derecho Público, 35. Universidad de los Andes (Colombia).

** Abogado, politólogo y estudiante de la Maestría en Derecho de la Universidad de los Andes. Investigador del Departamento de Ciencia Política de la misma universidad. Correo: s.virguez1345@uniandes.edu.co

Agradezco al profesor Rodolfo Arango Rivadeneira por sus certeros comentarios a lo largo de la elaboración de este artículo, y su disposición constante para la discusión de las muchas interrogantes que surgieron en el proceso. 


\section{Introducción: democracia y constitucionalismo en tensión}

Hablar de democracias constitucionales en las sociedades actuales parece ser un tema pacífico, de hecho, se han llegado a imponer visiones que sostienen que las constituciones consagran y aseguran los derechos centrales y necesarios para la misma democracia (Bellamy, 2007). De forma intuitiva, se tiende a relacionar régimen democrático con cartas de derechos que protegen desde libertades individuales (expresión, credo, locomoción, etc.), hasta contenidos socio-económicos e incluso ambientales. ${ }^{1}$

Sin embargo, como lo muestra gran parte de la literatura (Holmes, 1997; Sunstein, 1997; Schneider, 2000; Gargarella, 2014; entre otros), constitucionalismo, entendido como el sistema que establece derechos jurídicos individuales que el legislativo no puede anular o transgredir (Dworkin, 1995), ${ }^{2}$ y democracia, entendida bajo la famosa expresión de Abraham Lincoln como "el gobierno del pueblo, por el pueblo y para el pueblo", son conceptos que constantemente se encuentran en contradicción. Así lo muestran las documentaciones históricas hechas por Maurizio Fioravanti (2011), quien precisamente

1 El "nuevo constitucionalismo latinoamericano" constituye un ejemplo claro de esa relación intuitiva entre democracia y cartas de derechos. Como bien lo muestran Gargarella y Courtis (2009), en respuesta a los problemas de democracia ocacionados por las dictaduras, crisis institucionales y programas de reajuste económico estructural, los países latinoamericanos adoptaron amplios catálogos pretendiendo con ello una mejoría de las prácticas políticas democráticas.

2 Cabe recordar que el constitucionalismo no solo consagra la protección de derechos individuales, inmunes a la legislación ordinaria, sino también la organización del poder político. Sin embargo, cuando se haga referencia al constitucionalismo en el presente escrito se estará hablando solamente de la dimensión dogmática de derechos. rastrea teóricamente ${ }^{3}$ la tensión entre el autogobierno democrático y, lo que él identifica como criterio principal de la Constitución Moderna, la garantía de derechos individuales. Fioravanti logra mostrar cómo mientras la definición democrática de la soberanía, soberanía popular, fue ganando terreno junto con la idea de autogobierno, las preocupaciones (muchas veces liberales, pero en ocasiones republicanas como el caso norteamericano) por las decisiones tiránicas de las mayorías llevaron a pensar en la introducción de cartas de protección de libertades individuales intrínsecas al ser humano.

El momento constituyente norteamericano representa un ejemplo claro de cómo la tensión entre constitucionalismo y democracia ha surgido en las etapas de organización política institucional (donde se quieren pensar estructuras de autogobierno que a su vez respeten los derechos individuales) y, luego, ha persistido a lo largo de la práctica política. En este sentido, Madison, en El Federalista $X$, identifica el problema en estos términos:

Este examen del problema permite concluir que una democracia pura, por la que entiendo una sociedad integrada por un reducido número de ciudadanos, que reúnen y administran personalmente el gobierno, no puede evitar los riesgos del espíritu sectario. En casi todos los casos, la mayoría sentirá un interés o una pasión comunes (...) y nada podrá atajar las circunstancias que incitan a sacrificar al partido

3 A través de la revisión de los textos y las ideas principales de Jean Bodino, Thomas Hobbes, Jacques Rousseau, John Locke, James Harrington, Barón de Montesquieu, Immanuel Kant, Edmund Burke, Thomas Jefferson, James Madison, entre otros. 
más débil o algún sujeto odiado. Por eso estas democracias (...) han sido siempre incompatibles con la seguridad personal y los derechos de propiedad (...) (2001, pág. 39).

Esta tensión torna relevante la pregunta acerca de si las cartas constitucionales, que consagran derechos inmunes a la legislación ordinaria y al sentir de las mayorías, son compatibles o no con un régimen democrático; es decir, si el atrincheramiento de ciertas garantías en constituciones de difícil reforma debe entenderse como una acción antidemocrática o en cambio es una acción funcional a la democracia. Este escrito busca examinar esta pregunta a través del debate entre dos teóricos notables: Ronald Dworkin y Jeremy Waldron. Ambos autores parten de la idea de que la democracia requiere la protección efectiva de ciertos derechos básicos; sin embargo, mientras que Dworkin defiende la constitucionalización de aquellos derechos que considera necesarios para el ejercicio democrático, Waldron concibe un modelo de democracia que no contempla la existencia de una Constitución como mecanismo de protección de aquellos derechos.

En primer lugar, se sostendrá que la literatura ha errado en la idea de identificar como principal punto de discusión entre Dworkin y Waldron sus concepciones de democracia, sustantiva para el primero y procedimental para el segundo. Ambos autores llegan a reconocer el carácter sustantivo de la democracia; no obstante, su principal diferencia gira en torno a si aquellos mínimos sustantivos, sobre los cuales hay desacuerdo, deben ser protegidos mediante cartas constitu- cionales que los sustraigan del debate democrático de mayorías (bajo la cual se encuentra la legislación ordinaria).

En segundo lugar, se sustentará la tesis de que la constitucionalización de derechos no es incompatible con la democracia ni anula totalmente el desacuerdo. Los derechos necesarios para la democracia parten de una cultura de los derechos compartida en las comunidades actuales, y gozan de cierta objetividad que les permite sustraerse de las decisiones de las mayorías, sin que esto signifique que exista consenso general sobre su contenido (como lo demuestra la práctica jurídica constitucional).

Para desarrollar las tesis enunciadas se expondrán, en la primera sección, las principales líneas de discusión entre ambos autores, atendiendo a un contexto y a una cronología bibliográfica que permita identificarlas de una forma mucho más clara. En la segunda sección, se describirán brevemente los modelos de democracia que ambos autores proponen: democracia mayoritaria para el caso de Waldron y democracia asociativa para el caso de Dworkin, así como la relación que estos modelos guardan con el constitucionalismo. En la tercera sección se sustentarán las tesis propuestas, identificando ejemplos y posibles contraargumentos, para luego, por último, brindar algunas conclusiones.

Este escrito busca cumplir dos objetivos fundamentales. En primer lugar, la bibliografía existente no se ha ocupado de identificar las principales líneas de discusión que enfrentan las teorías de democracia y constitucionalismo de 
Ronald Dworkin y Jeremy Waldron, por esta razón, pretende no solo llenar ese vacío en la literatura a través de la documentación temática y bibliográfica del debate, sino también identificar el verdadero punto de desacuerdo entre ambos autores. En segundo lugar, busca extender la defensa de la idea de que el constitucionalismo no es contradictorio con el autogobierno democrático y por lo tanto se puede hablar, sin caer en un oxímoron, de democracias constitucionales.

\section{EL DEBATE WALDRON-DWORKIN EN CONTEXTO: LÍNEAS PRINCIPALES DE DISCUSIÓN}

Ronald Dworkin y Jeremy Waldron (alumno de Dworkin durante el doctorado en Oxford) sostuvieron un extenso debate acerca de la tensión entre la constitucionalización de derechos y el autogobierno en democracia, y más específicamente acerca del carácter democrático del control judicial a las leyes por parte de tribunales superiores. Claramente, sus posiciones al respecto constituyen solo una parte de un conjunto más amplio de reflexiones en torno a la política y el derecho, sin embargo, es menester limitarse a aquellos argumentos que ambos autores han planteado específicamente sobre la tensión referida en este ensayo.

En esta primera parte se pretende exponer los principales puntos de discusión entre Waldron y Dworkin, a través de una selección de aquellos escritos en que cada autor realizó expresa referencia acerca de las tesis del otro. La descripción más amplia de sus modelos de democracia (constitucional o no) se realizará en la siguiente sección, por el momento se dará un contexto general identificando tres líneas básicas de debate: (i) la conveniencia o no de la adopción de cartas constitucionales de derechos, (ii) el carácter democrático de las constituciones y del control judicial de las leyes y (iii) la correcta justificación o legitimidad de las decisiones políticas.

\section{A. ¿Son necesarias las cartas constitucionales de derechos?}

En el Reino Unido, como es sabido, no existe una carta constitucional escrita bien definida (un código constitucional, si se puede decir). A pesar de la importancia de documentos como la Carta Magna, el Bill of Rights o el Acta de la Unión de 1707, estos no tienen un carácter superior sobre la demás legislación. ${ }^{4}$ Esto se debe, como lo expone Anthony Bradley (1998), al principio de soberanía parlamentaria que rige al sistema político británico y por el cual la legislación expedida por el Parlamento es fuente principal de derecho, haciendo de esta institución el máximo órgano legislativo. No existen así normas o principios superiores que condicionen o limiten la legislación ordinaria.

Partiendo de ese contexto, en 1990 Dworkin publica un breve ensayo titulado A Bill of Rights

Ciertamente, puede que sea de común aceptación por parte del Parlamento que estos documentos cuenten con un valor superior que debe ser respetado por la legislación posterior, empero, de forma oficial estos cuentan con el mismo rango de ley. Una sentencia proferida por el Lord Justice John Laws en el caso Thoburn (2002), reconoce el carácter especial y superior de dichos estatutos constitucionales; no obstante, esa reflexión era obiter y por lo tanto no tiene valor vinculante. 
for Britain?, en el cual básicamente defiende la adopción de una Constitución escrita para el Reino Unido. Haciendo expresa referencia a François Furet, advierte que la señal de triunfo de la democracia en la actualidad es la aceptación de que esta no es equivalente a la "regla de mayorías" (decisión mayoritaria), sino que está constituida por la protección legal de las libertades y las minorías a través de constituciones escritas que no pueden ser modificadas por los parlamentos. De ahí que un verdadero sistema democrático deba contener una carta de derechos constitucionales individuales (derechos fundamentales), cuya protección sea encargada a jueces no elegidos y por lo tanto blindados ante las presiones de la política partidista (Dworkin, 1990a).

Este autor continúa afirmando que, a pesar de que la incorporación de la Convención Europea de Derechos Humanos a la legislación británica se pudiera entender como la adopción de una carta superior de derechos, el Reino Unido requiere de una Constitución nacional que permita a los ciudadanos defender sus libertades básicas frente al poder ilimitado del Parlamento. Además, concluye al respecto, la democracia no puede ser confundida con el poder de los funcionarios elegidos a través del voto, sino que su forma genuina requiere el respeto de dichos derechos básicos (como condición de existencia de la misma democracia) y por lo tanto la restricción de las decisiones legislativas conforme a aquellos (Dworkin, 1990a).

En respuesta a esta posición, Jeremy Waldron publica el ensayo A Right-Based Critique of
Constitutional Rights (1993), ${ }^{5}$ escrito mediante el cual pretende desestimar la necesidad de una Constitución para la protección de los derechos o libertades básicas de los ciudadanos. Son tres los principales argumentos que esgrime Waldron en respuesta a Dworkin:

En primer lugar, afirma que de una teoría basada en derechos no se sigue de forma necesaria un compromiso con una Constitución que esté por encima de la legislación ordinaria. Esto en cuanto a que a pesar de que las democracias requieren de ciertos derechos morales, de estos no se infiere necesariamente la existencia de derechos jurídicos y mucho menos de una instancia mayor de protección. Para ejemplificar esta posición, Waldron se refiere a cómo el reclamo moral de refugio por parte de una persona no es suficiente para que aquella pretenda ser titular de un derecho jurídico (mucho menos constitucional) que le garantice vivienda alguna:

El reclamo moral de que las personas tienen derecho a un lugar donde refugiarse es un reclamo sobre la importancia de que dispongan de dicho lugar, y no sobre de [sic] la importancia de que se les asigne un lugar de refugio de acuerdo a [sic] un tipo específico de procedimiento jurídico o burocrático (Waldron, 2005b, pág. 261).

En segundo lugar, Waldron (2005b) Ilama la atención sobre dos objeciones de un carácter más sustantivo frente a la constitucionalización de derechos. Parte de la premisa de que lo que

$5 \quad$ En el presente texto se toma la versión reimpresa de este ensayo en el libro Derecho y Desacuerdos (2005). 
se pretende hacer cuando se atrincheran derechos en cartas constitucionales es darles una inmunidad frente al cambio legislativo, lo cual suscita dos problemas principales: (i) por una parte se desconoce la controversia que existe en torno a la definición de estos, ya que una circunstancia básica de la política (y por lo tanto de sus decisiones) es el desacuerdo. El sustraer del debate legislativo unos derechos supone su definición, pero como no existe consenso al respecto no podríamos hacer la sustracción sin tomar partido por una visión o interpretación particular de aquellos; para Waldron, los autores que basan sus teorías en derechos (como Dworkin) presuponen que hay ciertos derechos morales indiscutibles sobre los cuales no hay desacuerdo alguno:

En el ámbito de los derechos, en el que precisamente están en juego cuestiones de relativa urgencia y prioridad moral, todos creen que han identificado correctamente las prioridades, y que los demás lo han hecho mal. Aunque todos deberían pensar que es posible que estén equivocados, no es necesariamente una buena idea incorporar esa duda en la fábrica de su teoría (Waldron, 2005b, pág. 269).

(ii) Por otra parte, el atrincherar derechos en una Constitución, dice Waldron (2005b), supone una actitud de desconfianza hacia los conciudadanos, lo cual no encaja bien con la idea de respeto por la autonomía y responsabilidad que transmite el mismo contenido sustantivo de dichos derechos atrincherados. Así, este autor identifica una contradicción advirtiendo que si la relevancia sustantiva de los derechos básicos que se buscan proteger se basa en que la persona es un sujeto pensante, capacitado para deliberar moralmente e ir más allá de una preocupación por la satisfacción de sus propios intereses, no habría motivo para cambiar de opinión y desconfiar de cualquier decisión legislativa que se tome. Pero si se tiene que la necesidad de constituciones que resguarden derechos frente a las decisiones legislativas está dada por una concepción predadora de la naturaleza humana, no habría razón para que las personas (egoístas por naturaleza) fueran en sí portadoras de derechos.

Por último, Jeremy Waldron (2005b) concluye en su texto que dado que una de las "circunstancias de la política" (pág. 123) -la idea de que existe desacuerdo sobre las cuestiones políticas fundamentales- es aplicable a las cuestiones de derechos, es decir que existe una discusión permanente acerca del contenido de aquellos, se debe prestar mayor atención a los procedimientos mediante los cuales se adoptan dichos derechos en vez de buscar sus contenidos correctos, ya que es un ejercicio inútil en comunidades que parten de condiciones de desacuerdo.

La discusión entre Dworkin y Waldron acerca de la adopción de cartas de derechos está basada en el modelo constitucional norteamericano. Es necesario tener en cuenta este contexto ya que los argumentos de ambos autores parten de la premisa de que la constitucionalización de un derecho supone hacer imposible o muy difícil la alteración de su contenido; sin embargo, no todos los regímenes constitucionales son de carácter rígido como el norteamericano y, por 
lo tanto, la reforma constitucional de sus derechos no es tan compleja, ya que solo requieren de algunas mayorías superiores en sus órganos legislativos para modificar dichas libertades.

\section{B. ¿Son las constituciones y el control constitucional democráticos?}

Hacia 1996 Ronald Dworkin recoge en la introducción de su libro Freedom 's Law los principales argumentos que ya había estado construyendo desde 1990 como respuesta a la tesis de Waldron (entre otros autores). En este texto son claras las críticas de Dworkin a los autores seguidores de la que él llama la "premisa mayoritaria" o la "concepción mayoritaria de la democracia", la cual reconoce (como lo muestran las tesis de Waldron) la existencia de derechos morales pero cuya definición depende de las decisiones de las mayorías. ${ }^{6}$

Para Dworkin (1996) el objetivo definitorio de la democracia no puede ser entendido simplemente como que las decisiones colectivas sean favorecidas por una mayoría, sino que dichas decisiones deben ser adoptadas por instituciones políticas que traten a todos los individuos con igual consideración y respeto. Esta idea es la que da sustento a la que el mismo Dworkin llamará "concepción constitucional de la democracia", la cual es descrita por él en los siguientes términos:

6 En este punto vuelve a tomar Dworkin los ejemplos británico y norteamericano, identificando al primero con una tradición fiel a la premisa mayoritaria y al segundo con el modelo constitucional de protección de derechos como triunfos sobre las mayorías (modelo que intenta defender).
La concepción constitucional de la democracia adopta la siguiente actitud frente al gobierno mayoritario. Democracia significa gobierno sujeto a condiciones, las cuales podríamos denominar condiciones democráticas de igualdad de estatus para todos los ciudadanos. Cuando las instituciones mayoritarias proveen y respetan las condiciones democráticas, entonces el veredicto de estas instituciones debería ser aceptado por todos por esa razón. Pero cuando no lo hacen, o cuando no las proveen o respetan suficientemente, entonces no pueden objetarse, en nombre de la democracia, otros procedimientos que protejan y respeten mejor esas condiciones (1996, págs. 117-118).

Para aquellos defensores de la premisa mayoritaria, como Waldron, el constitucionalismo debe entenderse de forma contraria a la democracia dado que, primero, se limita a proteger libertades negativas (en términos de Isaiah Berlin) y, segundo, socava en su oficio las libertades positivas de autogobierno. Sin embargo, afirma Dworkin (1996), la concepción mayoritaria solo puede garantizar el autogobierno democrático cuando garantiza también las condiciones de pertenencia moral de los ciudadanos a la comunidad, esto debido a que solo es posible que las personas acepten las decisiones de la mayoría, que pueden ser contrarias a su pensamiento, cuando estas las tratan con igual consideración y respeto. Que una persona se sienta autogobernada pese a someterse a la voluntad de los otros solo se debe al hecho de ser un miembro genuino de la comunidad política, y esto solo es posible cuando recibe un trato de igual consideración por su ser, de ahí que las condiciones de pertenencia moral se erijan como condiciones de democracia. 
La garantía de esas condiciones democráticas, continua Dworkin (1996), solo se puede dar bajo el supuesto de que la acción política colectiva se entienda de forma comunitaria y no individual o estadística. La acción colectiva es estadística cuando se entiende que es la simple agregación de lo que los miembros individuales hacen por sí, mientras que es comunitaria cuando se requiere que los individuos asuman la existencia de un grupo como "fenómeno por sí mismo" (Dworkin, 2006, pág. 10), es decir, que su actuar no se entiende como simple expresión de su individualidad sino como una agencia especial unificada. ${ }^{\top}$

Termina este autor diciendo que la crítica a la revisión judicial (control de constitucionalidad de las leyes) es simplemente hija de la concepción mayoritaria de la democracia y, por lo tanto, si se tiene que el constitucionalismo no socava la democracia sino que antes protege sus condiciones, el control que ejercen los jueces no es más que una extensión de esa protección.

En el año 1997, Jeremy Waldron en su ensayo The Constitutional Conception of Democracy discute las tesis hechas por Dworkin en Freedom 's Law. Un año después vuelve sobre los mismos argumentos en su artículo Judicial Review and the Conditions of Democracy (1998). Waldron

7 Un ejemplo de acción colectiva estadística es el mercado de divisas, el cual solo puede verse afectado sustancialmente a través del efecto combinado de un amplio conjunto de transacciones individuales (relaciones entre banqueros $u$ hombres de negocios). Un ejemplo de acción colectiva comunitaria es la interpretación de una sinfonía por parte de una orquesta, interpretación que no puede ser llevada a cabo por un solo músico sino que requiere de un conjunto más amplio (no se trata de agregación de individualidades sino de una acción que requiere un conjunto). (2005c) retoma la idea de una congruencia entre derechos y democracia y da razón a Dworkin al reconocer que no se puede concebir contradicción alguna entre la existencia de ciertos derechos morales y un régimen democrático. De esta forma, reconoce la existencia de dos tipos de derechos, aquellos constitutivos del proceso democrático (especialmente el derecho a la participación política) y aquellos necesarios para darle legitimidad, coincidiendo así con Dworkin sobre la idea de que las decisiones de las mayorías requieren ciertas condiciones que les den sentido moral.

Waldron critica en el texto la afirmación de Dworkin acerca de que el modelo norteamericano de arreglos constitucionales es democrático aun cuando establece un control judicial de constitucionalidad, mas no discute la tesis de que dicho control sea necesario para la democracia. En este sentido, explica que Dworkin no tiene en cuenta los medios o procedimientos por los cuales se toman las decisiones concernientes a las condiciones de democracia o a las mismas cuestiones de legislación ordinaria, sino que simplemente evalúa su carácter democrático por su contenido final, y por lo tanto afirma que “las preocupaciones sobre el carácter democrático o no democrático de un procedimiento político no se evaporan cuando el procedimiento en cuestión está siendo utilizado para ocuparse de una cuestión sobre la naturaleza de la democracia" (2005c, pág. 350). Para este autor, los procedimientos no son irrelevantes y ciertamente se "pierde algo" (2005c, pág. 351) desde el punto de vista democrático cuando funcionarios no electos toman decisiones vinculantes acerca 
de lo que implica la democracia. En pocas palabras, Waldron sostiene que sin importar que las decisiones que se tomen a través del control de constitucionalidad sean acordes, sustantivamente, con la idea de democracia (respeten la igual consideración y respeto por todos), el hecho de que sean jueces no elegidos quienes las adopten, sin intervención de ninguna otra persona, hace que aquellas pierdan cierta legitimidad democrática. Esto hace que dicho mecanismo de revisión judicial no pueda ser de carácter democrático.

Además de su crítica al mecanismo de control de constitucionalidad, Waldron (2005c) vuelve a exponer su idea del desacuerdo como argumento principal en contra de la constitucionalización de derechos. Recuerda el que a pesar de que los ciudadanos pueden coincidir en la idea de que ciertos derechos son condiciones necesarias para el ejercicio democrático, sobre cuáles son esos derechos y a qué específicamente comprometen, persiste una discrepancia general. Así mismo, reconoce que también existe discusión sobre los mismos mecanismos adecuados para solucionar los desacuerdos; no obstante, la elección del voto (la decisión por mayorías) como método para decidir sobre las cuestiones políticas fundamentales y ordinarias sería una petición de principio, es decir que se elige simplemente porque en las circunstancias de desacuerdo se necesita de un procedimiento y aquel parece el más adecuado.

\section{C. ¿Qué legitima la regla mayoritaria? EI caso del "lifeboat"}

El desacuerdo sobre la elección del voto mayoritario como mecanismo de solución de controversias (que se mencionó anteriormente) suscitó un interesante debate entre Dworkin y Waldron en torno a un simple ejemplo. En su texto The Core of the Case Against Judicial Review (2006), Waldron intentó dar respuesta a un problema que le expuso Dworkin en una conversación: cuando un bote salvavidas está con sobrecupo y por lo tanto un pasajero debe ser lanzado al agua, donde seguramente morirá, no sería justo sostener una votación ya que la persona menos popular entre los pasajeros terminaría siendo el afectado; en cambio, sería más justo dejar esa decisión al azar. Frente a esta situación, Waldron (2006) afirmó que si los pasajeros difieren acerca de si es más adecuada la votación o el azar, la única manera justa de terminar la disputa sería votar acerca de cuál es el procedimiento correcto.

En los manuscritos sin publicar de Justice for Hedgehogs, Dworkin dio respuesta simple ante el argumento de Waldron. No hay razón para entender que realizar una primera votación para decidir si se debe tener una elección y luego una segunda votación para decidir a quién lanzar del bote otorgue mayor legitimidad o justicia a la decisión; para Dworkin, si es controversial la elección sobre el correcto procedimiento para decidir cuestiones políticas en condiciones de desacuerdo, es controversial de ahí en adelante y por ello no puede existir una decisión del procedimiento por defecto. El punto principal de la 
respuesta es que el principio de mayorías no es un principio general de fairness, independiente del contexto (no es intrínsecamente justo).

Luego, en su artículo A Majority in the Lifeboat (2010), Waldron expone que el ejemplo del bote salvavidas no dice nada acerca de la concepción mayoritaria de la democracia. Frente al ejemplo, reconoce que los pasajeros deben contar con un menú de opciones sobre los procedimientos que pueden adoptar para decidir quién debe saltar del bote; sin embargo, en el menú no puede haber ninguna opción que suponga a priori la decisión acerca de quién debe abandonar el bote, es decir, que ninguna opción debe ser sesgada o parcializada hacia alguna decisión. Pero, de nuevo, afirma Waldron que el argumento sobre la legitimidad de la decisión mayoritaria que supone el ejemplo no es suficiente para responder a las críticas que ha hecho sobre las cartas constitucionales y el control judicial de constitucionalidad.

En la versión publicada de Justice for Hedgehogs (2011), Dworkin zanja la discusión aceptando que efectivamente ninguna opción de procedimiento presentada a los pasajeros del bote debe sesgar su decisión posterior acerca de quién debe abandonarlo, y a su vez reconoce que el ejemplo planteado no es argumento suficiente para responder a la premisa mayoritaria. Termina afirmando que la solución al problema es simple: se debe elegir la suerte como el mecanismo de decisión; sin embargo, sostiene que la opción del azar no puede ser apropiada para las decisiones de procedimiento en política ya que estas conllevan importantes consecuencias sobre la vida de las personas y, por lo tanto, dejar todo a la suerte parecería una mala idea.

En este aparte se intentó realizar un corto resumen acerca de las principales líneas de discusión que han dado forma al debate entre Ronald Dworkin y Jeremy Waldron, bajo un contexto histórico, bibliográfico y temático que permite evidenciar de una mejor forma aquellos puntos de conexión entre ambos autores y aquellos puntos de desacuerdo. Parece claro que para Waldron las cartas constitucionales y el control de constitucionalidad como mecanismo de protección de estas no tienen un carácter democrático; en cambio, para Dworkin se hace necesario en la práctica democrática que los jueces sean quienes deban garantizar el cumplimiento de derechos constitucionales de mayor protección.

No obstante, para entender de forma más clara dichas líneas de discusión entre los dos autores, es relevante referirse a las concepciones de democracia que cada uno de ellos sostiene y su relación con el constitucionalismo.

\section{DOS MODELOS DE DEMOCRACIA Y SU RELACIÓN CON EL CONSTITUCIONALISMO}

El debate en torno al carácter democrático del constitucionalismo es abordado por Waldron y Dworkin como una discusión más amplia sobre diferentes concepciones de democracia; puede decirse que ambos autores se apartan de discusiones que suponen una pasividad conceptual acerca de cómo entender Constitución, de- 
mocracia, derechos morales, etc., y en cambio proponen estudiar las tensiones en el mismo plano de construcción conceptual. En pocas palabras, no se puede entender la tensión entre constitucionalismo y democracia, y brindar una solución al respecto, sin antes reflexionar acerca de qué quieren decir ambos conceptos, cuáles son sus características y cuáles son sus objetivos definitorios.

En este aparte se exponen los dos modelos de democracia que proponen ambos autores y su relación con el constitucionalismo, de una forma clara y concreta, ya no atendiendo a una cronología bibliográfica como en la sección anterior, sino a una descripción más organizada a partir de los principales puntos que Dworkin y Waldron han brindado al respecto a lo largo de su obra.

\section{A. El modelo democrático de mayorías. Un modelo procedimental}

Jeremy Waldron (1993, 1997, 1998, 2005a y 2006) ha defendido una concepción de la democracia acorde con la premisa mayoritaria. Esta sostiene que las decisiones políticas fundamentales y ordinarias deben ser decididas a partir de mecanismos de votación, en los que cada ciudadano de forma individual expresa su preferencia y al final la mayor agregación de un punto de vista determinado prevalece con fuerza vinculante, incluso sobre los que no lo compartían. Para este autor, el proceso de mayorías se erige como el procedimiento más justo para decidir las cuestiones políticas de forma democrática, ya que es neutral frente a las preferencias de los individuos en las cuestiones a decidir (no sesga la decisión hacia algún punto de vista); permite la participación directa de toda la ciudadanía (en aras de proteger el autogobierno colectivo); y trata a cada uno de dichos ciudadanos de forma igual al otorgar igual peso a cada uno de sus puntos de vista, a través de la simple fórmula: una persona, un voto.

Este modelo, como lo señala Dworkin (1990b), responde a una forma estadística de acción colectiva, la cual es una función aproximada de lo que los miembros individuales hacen por sí mismos, sin tener conciencia de estar haciendo algo como una comunidad. Las decisiones políticas que son legítimas bajo este marco de acción son aquellas que agreguen más adhesiones individuales en las urnas; de ahí que se tenga como un modelo de democracia liberal clásico que concibe a los ciudadanos como individuos que persiguen sus propios intereses, los cuales están muchas veces en oposicion y por eso se hace necesario la elección de mayorías para determinar los cursos de acción común.

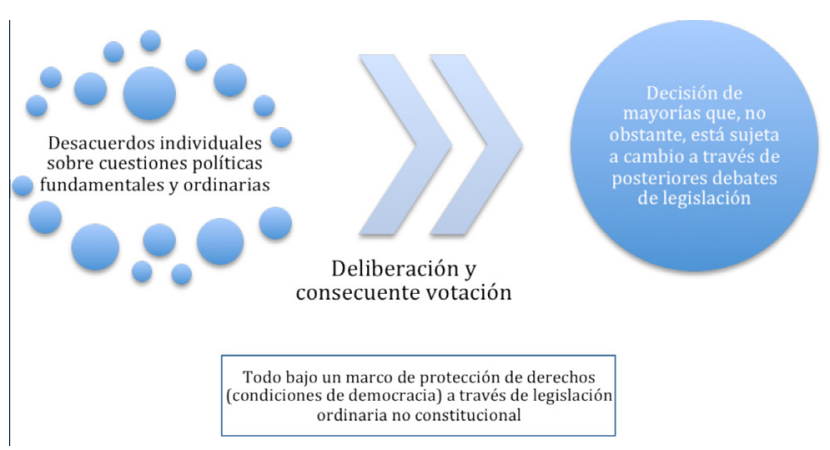

Fuente: elaboración propia a partir de Waldron (2005a).

\section{El desacuerdo como fundamento de la concepción mayoritaria de la democracia}

Que se acuda a las urnas y a las decisiones de la mayoría se hace necesario debido a las 
dos circunstancias de la política que identifica Waldron (2005a): la existencia de desacuerdos y la necesidad de un curso de acción común. Este autor comparte con teóricos comunitarios como Walzer y Sandel, o feministas como Mackinnon, una crítica interesante a la tendencia homogeneizadora del liberalismo contemporáneo y su obsesión por el consenso, reconociendo que el rasgo más distintivo de la política es que su punto de partida es el hecho de los desacuerdos.

Existen profundos desacuerdos sobre cualquier elemento de la organización social y política, lo cual antes que ser un obstáculo es un factor que hace posible y enriquece la deliberación democrática. No obstante, a pesar de discrepar sobre todas las cuestiones políticas los ciudadanos requieren, para Waldron, de un curso de acción común para continuar conviviendo; tampoco se debería seguir de la teoría del desacuerdo que cada individuo simplemente deba hacer lo que quiera, sino que hay que tomar decisiones que vinculen a todos. Es por esa segunda condición de la política (curso de acción común) que se requiere un mecanismo imparcial para decidir las cuestiones políticas tanto fundamentales como ordinarias.

\section{La votación como resultado natural del desacuerdo y la deliberación}

En línea con su crítica a la tendencia homogeneizante del liberalismo contemporáneo, el cual sostiene que del discurso (discusión) se sigue el consenso, Waldron (2004) insiste en la idea de que la toma de decisiones por me- dio de votaciones es el resultado normal de una deliberación en condiciones de desacuerdo. Este autor identifica la supuesta repugnancia que hoy se entiende sobre el voto mayoritario como consecuencia común de la deliberación, de esta forma:

La deliberación, se nos dice, se dirige principalmente al consenso; no obstante, es solo en circunstancias de disenso (una diversidad de opiniones o posiciones no resueltas) en las que se busca algo como la votación. Como último recurso, tal vez, cuando la deliberación parece inútil para llevarnos más lejos, podríamos sinceramente contar cabezas y ver cuál de las posiciones en competencia tiene mayor apoyo. Pero hay algo vergonzante sobre la votación en un contexto deliberativo (Waldron, 2004, págs. 250-251).

Así, comúnmente se entiende que la votación por mayoría solo puede adoptarse cuando la deliberación falla en la búsqueda del consenso. Sin embargo, se debe partir de la premisa de que el consenso no es esperable generalmente en la política, de lo cual se sigue que no debe haber contradicción alguna entre la deliberación y el voto mayoritario (antes bien existe entre estas una relación complementaria). La deliberación puede llevar al consenso; no obstante, su objetivo principal es poner en conocimiento las bases del desacuerdo y dar una descripción razonable de lo que está en disputa. Y es, afirma Waldron (2004), precisamente lo que muestra el ejemplo de la toma de decisiones en los tribunales judiciales, donde partiendo de un desacuerdo sobre alguna cuestión constitucional los jueces deliberan y al final, como requieren tomar una 
decisión frente al dilema planteado, deciden a través del voto de mayorías. ${ }^{8}$

Ante el desacuerdo: deliberación y votación. En este punto se ve marcado el supuesto carácter procedimental de la propuesta de Waldron en el sentido de que lo esencial para él es la posibilidad de participar de las decisiones políticas, sin importar el resultado. Al respecto afirma que, cuando una decisión política fundamental es tomada por una institución no electa ni responsable (unaccountable) algo se pierde desde el punto de vista democrático, ${ }^{9}$ así su contenido produzca un beneficio para la democracia; pero si la institución es electa y responsable (accountable), así se produzca alguna pérdida para la democracia en el contenido de su decisión, parece sensato decir que al menos no se afecta la idea de autogobierno (Waldron, 2005c). De ahí que Waldron se ocupe del derecho a la participación en términos del "derecho de los derechos" (Waldron, 2005c, pág. 337).

\section{Constitucionalismo y democracia no van de la mano}

De la línea argumentativa que se ha expuesto (en esta y en la anterior sección) se sigue que el modelo de democracia mayoritaria que defiende Waldron no camina de la mano con el constitucionalismo. Ciertamente es la circunstancia del desacuerdo lo que más motiva a este autor a rechazar la constitucionalización de ciertos derechos que incluso él acepta como mínimos necesarios (desde una perspectiva procedimental o de legitimidad) para el desarrollo de una democracia. Al respecto afirma:

Pero una ciudadanía que discrepa sobre cuáles son los resultados correctos no está en situación de edificar su Constitución sobre esta base (...) Si utilizamos un enfoque que atienda a los resultados, distintos ciudadanos intentarán diseñar la Constitución sobre fundamentos diversos. Un libertario buscará procedimientos participativos que maximicen las expectativas de una legislación justa, juzgada desde sus propios principios de libre mercado, mientras que un social demócrata tenderá a los procedimientos que incorporen una sensibilidad colectiva e igualitaria (Waldron, 2005c, pág. 352).

Para Waldron, constitucionalizar ciertos derechos implica tomar posición acerca de su contenido y darles cierta inmunidad frente a su reforma. Sin embargo, lo propio de la democracia es el disenso y por ello no habría razón para darle una protección especial a ciertas visiones de lo que debería ser el contenido de los derechos. Los mínimos, sustantivos y procedimentales, requeridos en un régimen democrático deben 
estar protegidos bajo una legislación ordinaria que esté sujeta a discusión constante y pueda ser reformada cuando las mayorías lo deseen (característica propia de la democracia para Waldron).

\section{B. El modelo asociativo de democracia. Un modelo sustantivo}

Ronald Dworkin (1989, 1990a, 1990b, 1996, 2006, 2011) mostró una increíble coherencia a lo largo de su obra acerca de cuál debía ser el modelo de democracia que debía oponerse a aquel concebido por los defensores de la premisa mayoritaria; este modelo fue conocido inicialmente como la "concepción constitucional de la democracia" y luego tomó el nombre de "modelo asociativo de democracia".

La visión asociativa de este autor sostiene que la democracia significa que las personas se gobiernan a sí mismas como socios de una empresa política colectiva, lo cual va más allá de que cada uno tenga un voto, y en cambio requiere que aquellos ciudadanos que comparten igual voz y voto también tengan una igual participación en el resultado de la decisión (Dworkin, 2011). Así, las decisiones mayoritarias solo serían democráticas cuando protegen los intereses de cada uno de los ciudadanos como socios plenos de una empresa colectiva (Dworkin, 2006). Entonces, la pregunta de partida es la siguiente: ¿por qué las decisiones políticas de las mayorías pueden ser legítimas aun cuando ciertos puntos de vista quedan derrotados? Que se acepte la legitimidad de una decisión tomada por la mayoría, aun cuando no es compar- tida por todos, solo es posible, afirma Dworkin (1990b), cuando todas las personas se sienten moralmente parte de aquella comunidad que decide, y esto solo será posible una vez se respeten ciertos principios o condiciones que brinden igual participación en el proceso de decisión e igual consideración en el resultado.

\section{La dignidad y las condiciones de la democracia asociativa}

Dworkin (2011) parte de dos dimensiones de la dignidad humana: por una parte, cada ser humano posee un valor objetivo intrínseco y ese valor es igual del de las demás personas; si cada persona reconoce su valor objetivo, debe reconocer necesariamente el valor objetivo de los demás, y a su vez estos tendrán que reconocer el valor de aquella. Por otra parte, cada ser humano cuenta con la responsabilidad de triunfar en su vida, lo cual implica elegir por sí mismo (no por otro) el modelo de vida exitosa que quiere tener (dimensión ética). Estas dos dimensiones no deben entenderse de forma meramente individualista, sino que se debe saber que el valor objetivo y la vida exitosa de cada persona no son independientes del valor y éxito de su comunidad.

De estas dos dimensiones de la dignidad humana Dworkin (1990b) extrae los principios básicos o condiciones de su modelo de democracia asociativa: (i) principio de participación, (ii) principio de interés y (iii) principio de independencia.

En primer lugar, la democracia entendida en un sentido asociativo requiere que cada persona 
tenga una participación efectiva en el proceso de toma de decisiones políticas y que esa participación sea igual a la de los demás. El primer elemento, que cada persona desempeñe un papel decisivo, está dado por el ideal del autogobierno democrático y busca que los ciudadanos puedan marcar una diferencia en el carácter de las decisiones políticas, diferencia que no puede estar determinada o limitada estructuralmente o por el poder de otros. El segundo elemento, que el papel decisivo con el que cuentan los ciudadanos sea igual, es el que hace realmente democrático todo el principio de participación ya que supone que cada ciudadano tiene el mismo impacto e influencia en los resultados políticos. ${ }^{10}$

En segundo lugar, si se tiene una democracia entendida desde la óptica de la acción colectiva comunitaria (en los términos que se expuso anteriormente), las decisiones políticas colectivas deben reflejar igual consideración por los intereses de todos sus miembros, ya que la calidad de miembro de una colectividad implica cierta reciprocidad con los demás. Como se explicó antes, para que una persona se sienta miembro moral de una comunidad, y por lo tanto acepte como legítimas sus decisiones políticas, se requiere que reciba igual respeto y consideración por parte de los otros miembros. Ello solo puede ser evaluado a través de un examen del contenido sustantivo de las decisiones tomadas. Afirma Dworkin:

La concepción comunitaria reúne la justicia procedimental con la sustantiva mediante la in-

10 Este principio parece ser compartido por todos aquellos que basan sus modelos de organización política bajo el ideal democrático. sistencia en que la democracia significa gobierno por y para el pueblo; bajo esta concepción, la distinción entre estas dos visiones de la justicia sólo es superficial. La cuestión acerca de cómo la comunidad trata a sus miembros es parte de lo que determina si éstos pertenecen y, por lo tanto, si las decisiones políticas son tomadas por un agente colectivo que los incluya (1990b, pág. 133).

De esta forma, puede verse cómo este principio determina el carácter sustantivo de la democracia asociativa, en donde son los resultados (no solo el procedimiento) los que definen el carácter democrático del régimen político y su contenido legislativo. Por ejemplo, el hecho de que se resuelva por mayorías (mediante un proceso de votación que otorga igual participación a todos a través de la fórmula un ciudadano, un voto) que de ahora en adelante solamente podrán acceder a cargos de elección popular aquellas personas que militen en los partidos políticos $A$ y $B$, excluyendo así a quienes hagan parte de otras fuerzas políticas, constituye una decisión que, a pesar de ser el resultado de un proceso que cuenta con igualdad de participación, no otorga igual consideración y respeto a todos los miembros de la comunidad y por lo tanto no puede afirmarse que tenga un carácter democrático.

En tercer lugar, mientras el principio de interés distingue una democracia asociativa de una meramente mayoritaria o estadística, el principio de independencia la diferencia de una democracia comunitaria monolítica, en la cual las actitudes compartidas por los ciudadanos no solo crean una "unidad de responsabilidad colectiva" sino que también forman una "unidad 
de juicio colectiva" que anula la individualidad; ${ }^{11}$ en palabras más claras, el principio de independencia es aquel que salvaguarda la dimensión ética del individuo, por la cual de forma autónoma se forma juicios sobre el modelo de vida adecuado. Por lo anterior, afirma Dworkin (1990b), la democracia se subvierte cuando la comunidad adopta medios coactivos, de forma explícita o indirecta, para dar cierta forma a las convicciones de los ciudadanos.

\section{Las condiciones democráticas y el constitucionalismo}

En sus famosos libros Taking Right Seriously (1977) y A Matter of Principle (1985) Dworkin defendía ya la idea de la constitucionalización de los derechos morales necesarios en las sociedades democráticas. Si la democracia necesita para su existencia ciertas condiciones de pertenencia moral de los individuos hacia su comunidad, dichas condiciones deberían ser extraídas del debate legislativo ordinario para darles un rango constitucional superior que las mantenga fuera de cualquier intento de reforma por parte de las mayorías. Al respecto afirma Dworkin:

La Constitución, y particularmente la Bill of Rights, está diseñada para proteger a los ciudadanos individuales y a los grupos en contra

11 Un ejemplo de acción colectiva monolítica lo constituye un régimen de despotismo teocrático, en el cual aquel que sostuviera un conjunto independiente de convicciones sería un revolucionario, incluso si sus convicciones independientes adhirieran a la teocracia. En cambio, el principio de independencia distingue esa colección colectiva monolítica de una integrada cuyo ejemplo puede ser tomado de una orquesta; en esta se espera que los músicos desarrollen y conserven su propio sentido de logro musical a pesar de que la sinfonía solo pueda ser llevada a cabo en conjunto (Dworkin, 1990b). de ciertas decisiones que una mayoría de ciudadanos pudieran querer tomar, incluso cuando la mayoría actúa en lo que se tiene como interés general o común (1977, pág. 133).

La introducción de cartas constitucionales debe hacerse, afirma Dworkin (1977), en aras de proteger los derechos morales frente a mayorías que pueden socavar, en sus decisiones, dichas condiciones necesarias de democracia. Son esas mayorías meramente estadísticas, que precisamente no atienden a los principios de igual consideración y respeto sino a la agregación de intereses individuales, las que pueden poner en peligro aquellos principios claramente vinculados con la dignidad humana. Como se expondrá más adelante, la única forma de tomarse en serio los derechos básicos de una democracia es sustrayéndolos del sentir mayoritario, a través de la adopción de cartas constitucionales que les otorguen mayor estabilidad pese al desacuerdo sobre estos.

Finalmente, podría mostrarse aquí el mismo esquema presentado anteriormente sobre el modelo de democracia de Waldron, ya que comparte con el modelo asociativo su estructura general. Sin embargo, parece haber quedado claro que la concepción no contradictoria entre constitucionalismo y democracia en el modelo de Dworkin atiende a una concepción no individualista sino más comunitaria. A pesar de que se ha repetido constantemente esta idea a lo largo del texto, por ser el elemento central en este autor, cabe realizar una última referencia muy clara al respecto: 
Por fin podemos considerar nuestra hipótesis en forma directa: que la mejor defensa de la legitimidad política (...) no se hallará en el duro terreno de los contratos, deberes de justicia u obligaciones de juego limpio que pueden ser válidas entre extraños, donde los filósofos han esperado encontrarlos, sino en el terreno más fértil de la fraternidad, la comunidad, y sus obligaciones concomitantes (Dworkin, 1988, pág. 152).

\section{III. ¿SE PUEDE HABLAR DE UN CARÁCTER DEMOCRÁTICO DEL CONSTITUCIONALISMO?}

En este punto es posible ver cómo la teorías de Dworkin y Waldron en torno al problema planteado, la tensión entre constitucionalismo ${ }^{12}$ y democracia, parecen estar en abierta oposición. Mientras que el primero considera indispensable la adopción de cartas constitucionales de derechos para el desarrollo de la democracia, el segundo sostiene que las constituciones no tienen un carácter democrático dado que desconocen el desacuerdo. A continuación se sustentarán dos tesis principales: (i) el verdadero punto de discusión entre Dworkin y Waldron no es en torno a sus concepciones de democracia (procedimental o sustantiva), como lo ha sostenido la literatura, sino a la cuestión acerca de si la constitucionalización de derechos anula el desacuerdo y, por lo tanto, dado que el disenso es una propiedad intrínseca a la democracia, carece de un carácter democrático; y (ii) frente a

12 Es pertinente reiterar que a lo largo de este escrito se ha entendido el constitucionalismo como el sistema que establece derechos jurídicos individuales que el legislativo no puede anular o transgredir. este problema, se sostiene que existe una cultura jurídica y una objetividad de ciertos derechos fundamentales que permite sustraerlos de las mayorías a través de su constitucionalización, sin que aquello implique un desconocimiento del desacuerdo como condición de la democracia.

\section{A. Al final, dos modelos de democracia sustantiva}

Al describir los modelos de democracia de ambos autores, el modelo de mayorías de Waldron y el modelo asociativo de Dworkin, se planteó cómo uno parecía responder a un criterio procedimental y el otro a un criterio sustantivo. En principio, la democracia de mayorías parecía juzgar el carácter democrático de las decisiones políticas por el lado del input (procedimiento), mientras que la democracia asociativa realizaba el juicio democrático de aquellas desde el lado del output (contenido final). Del carácter procedimental o sustantivo de democracia se seguía, ciertamente, la posición a favor o en contra de la constitucionalización de derechos individuales sustantivos. Esa ha sido la diferencia que la literatura (Salazar, 2007; Bellamy, 2007; González Bertomeu, 2011; Colón-Ríos, 2012) ha identificado como principal punto de debate entre Dworkin y Waldron.

No obstante, una lectura detenida de la propuesta de Waldron permite observar que este autor termina defendiendo un concepto de democracia sustantiva a través del reconocimiento de derechos morales, no procedimentales, como condiciones necesarias de un régimen democrático. Como se expuso anteriormente, Waldron recono- 
ce la existencia de dos tipos de derechos en las democracias: (i) los derechos constitutivos del procedimiento democrático y (ii) los derechos que, aunque no sean formalmente constitutivos de democracia, representan condiciones necesarias para su legitimidad. Frente al segundo tipo de derechos afirma lo siguiente:

Además de aquellos que constituyen el proceso democrático, hay muchos derechos que pueden ser representados plausiblemente como condiciones de la legitimidad o de la respetabilidad moral de la toma de decisiones democráticas. Nadie piensa que un puñado de personas esté autorizado para imponer una decisión a los demás, simplemente porque haya más individuos a favor de la decisión que en contra. La democracia y la decisión mayoritaria solo tienen sentido moralmente bajo ciertas condiciones [cursivas fuera de texto] (Waldron, 2005c, pág. 339).

Y sigue más adelante:

Seguro que hay algunos derechos a los que, en caso de no ser respetados en una comunidad, no podría atribuirse ninguna legitimidad política a ningún procedimiento de decisión mayoritaria. ¿No es apropiado, entonces, que la toma de decisiones mayoritaria esté limitada por los derechos que satisfacen esa fórmula? Difícilmente podríamos lamentarnos de dichos límites en nombre de la democracia, puesto que una democracia no limitada por esos derechos casi no merecería su nombre (Waldron, 2005c, pág. 339).

Este argumento aparece en otros textos de Waldron (1993, 2006), en donde claramente supedita la legitimidad de las decisiones políticas tomadas por las mayorías, a través de un procedimiento de participación general, al respeto de ciertas condiciones sustantivas. Estas reflexiones tienden a inclinar a Waldron hacia el lado de la democracia sustantiva, dado que sería necesario revisar el contenido sustantivo final de las decisiones tomadas para poder determinar su legitimidad democrática. Lo anterior no quita el hecho de que este autor enfoca más su teoría en las condiciones de procedimiento y esencialmente en el derecho de participación.

De hecho, Waldron (2005c, pág. 341) reconoce que comparte la crítica que formula Dworkin a la tesis procedimentalista de John Hart Ely. Hay que recordar que Ely (1997) afirma que no puede sostenerse ninguna objeción democrática sobre aquellos derechos constitucionales, y su protección por vía de control judicial de constitucionalidad, que son procedimentalmente constitutivos de democracia, e incluso sobre aquellas disposiciones constitucionales que siendo expresamente restrictivas (de carácter sustantivo), desde un punto de vista funcional terminan siendo estructurales- procedimentales. ${ }^{13}$ Así, tanto Dworkin como Waldron rechazan limitar su atención sobre las condiciones de democracia a aquellas meramente constitutivas del procedimiento, por lo cual no puede afirmarse de forma clara que el modelo democrático de mayorías defendido por Waldron se agote en lo procedimental.

Pero, Waldron (2005c, pág. 349) no le hace a justicia a Dworkin cuando afirma que su modelo

13 Como por ejemplo la libertad de expresión cuyo contenido es sustantivo, pero que a su vez termina siendo funcional y necesaria en el procedimiento de decisión política democrática. 
de democracia no le otorga relevancia al proceso de formación política sino solamente al contenido de su resultado. Como se expuso en la descripción del modelo de democracia asociativa, una de sus condiciones básicas era el principio de participación por el cual cada persona cuenta con un papel en el proceso de toma de decisiones políticas, papel que es igual al de los demás. Esto torna relevante el procedimiento al momento de determinar el carácter democrático de una decisión.

De esta forma, el core del desacuerdo entre Dworkin y Waldron lo constituye la cuestión acerca de si esos derechos morales sustantivos que requiere la democracia deben ser o no derechos constitucionales, es decir, derechos que se sustraen de las mayorías y por lo tanto se tornan de difícil reforma. Sobre estos, afirma Waldron, existe desacuerdo y por lo tanto deberían estar sujetos a un debate democrático continuo (mediante el órgano legislativo) en vez de estar atrincherados en constituciones antidemocráticas.

\section{B. Democracia, desacuerdo $y$ constitucionalismo}

Jeremy Waldron, como se ha visto, sostiene que sobre los derechos morales sustantivos que requiere la democracia existen profundas discrepancias acerca de su definición y el alcance de su contenido; en este sentido, Waldron comparte las posiciones de autores como Rancière (1996) y de otros que fundamentan la democracia en el hecho del pluralismo y del disenso. Así, el constitucionalizar ciertos mínimos, procedimentales y sustantivos, es otorgarle inmunidad, frente al cambio legislativo, a posiciones concretas no imparciales que les dan un contenido específico a esos mínimos.

A continuación se sustentará la idea de que la constitucionalización de ciertos derechos morales (de carácter fundamental) es posible sin que ello implique la anulación total del desacuerdo en un régimen democrático. Tres argumentos dan fundamento a esta tesis: (i) las comunidades democráticas actuales comparten, como un hecho social, ${ }^{14}$ una cultura de los derechos que indica la necesidad de proteger ciertos derechos fundamentales frente al querer de las mayorías; (ii) es posible defender la objetividad de los derechos fundamentales para la democracia; y (iii) la práctica constitucional indica que el constitucionalizar los derechos no implica que sobre ellos no haya más discusión, ni que en ella no participen todos los ciudadanos.

\section{La cultura de los derechos como un hecho social compartido}

Las concepciones individualistas de la democracia, como el modelo de mayorías de Waldron, no tienen en cuenta los elementos o características que comparten los miembros en una comunidad. El individualismo concibe a los sujetos de forma aislada, con sus propias preferencias, y las comunidades como resultados contractuales de transacciones entre los distintos intereses. Sin ánimo de hacer referencia a su corrección normativa, cabe decir que estas

14 Se entiende como hecho social, en términos de Durkheim, aquellos modos de actuar, pensar y sentir externos al individuo, y que poseen un poder de coerción en virtud del cual se imponen a él. 
teorías individualistas de democracia desconocen el hecho de que aquellos sujetos nacen en comunidades ya establecidas, que históricamente han formado moralidades y costumbres que a su vez se erigen como hechos sociales, en términos de Durkheim, y por lo tanto son ajenas a la agencia individual pero subyacen su pensar y actuar.

Precisamente, en las sociedades actuales existe la que han llamado una cultura de los derechos humanos. Autores como Rodolfo Arango (2004) han afirmado que desde el siglo xx la cultura de los derechos humanos ha experimentado una rápida expansión, debido a su positivización e institucionalización en la mayoría de las constituciones políticas de las democracias de la segunda posguerra. De igual forma, comenta que a partir de documentos como la Declaración Mundial de los Derechos Humanos o el Estatuto Penal de Roma y la formación de organizaciones como las Naciones Unidas, la cultura de los derechos humanos se encuentra en todos los rincones de la tierra bajo presupuestos como lo son la aplicación de los derechos humanos a todas las personas (sin discriminación alguna), su validez irrestricta, o la responsabilidad de todos los Estados frente a su aplicación (deja de ser una cuestión interna de los Estados) (Arango, 2004).

Así mismo, Norberto Bobbio (1991) afirma que los debates actuales en torno a los derechos están enfocados en sus mecanismos de protección más que en su fundamentación, el cual es un tema que ya se entiende saldado. Al respecto dice:
Se entiende que la existencia del "respeto" a los derechos humanos y las libertades fundamentales nace de la convicción generalmente compartida de que ya están fundados: el problema del fundamento es ineludible. Pero cuando digo que el problema cada vez más urgente frente al que nos encontramos no es el problema del fundamento, sino el de las garantías, quiero decir que consideramos el problema del fundamento no como inexistente sino como, en un cierto sentido, resuelto, de tal modo que no debemos preocuparnos más de su solución. En efecto, hoy se puede decir que el problema del fundamento de los derechos humanos ha tenido su solución en la Declaración Universal de Derechos Humanos [cursivas fuera de texto] (Bobbio, 1991, pág. 64).

Con estas ideas se quiere poner de presente el hecho de que en las sociedades actuales ya existe una cultura de los derechos compartida, sobre la cual parten las deliberaciones políticas. Las personas parecen compartir nociones de dignidad o de justicia, por ejemplo, que no dependen de un desarrollo normativo previo sino que ya están instaladas en el trasfondo de las comunidades. Darle una lectura individualista al desacuerdo y a la democracia requiere desocializar al individuo, es decir, concebir a los sujetos como individuos previos a una colectividad, que no guardan ningún tipo de elemento común con los demás. En este sentido, hace bien Michael Sandel (2003) en caracterizar a este tipo de sujeto, que concibe las teorías liberales individualistas, como un yo desvinculado libre de los dictados de la naturaleza, de la determinación de los roles sociales y autor de los únicos significados morales que existen; no hay 
orden, costumbre, tradición o estatus heredado que lo ate.

Ciertamente, el hecho de reconocer que las personas comparten ciertos elementos, como la cultura de los derechos humanos, si bien permite comprender la posibilidad de lograr ciertos consensos sobre mínimos políticos, no implica acabar con la idea de que una condición de la política, en términos de Waldron, es la circunstancia del disenso. El background moral de las comunidades actuales permite extraer ciertas condiciones necesarias para la democracia, sin embargo, el alcance o las particularidades de dichas condiciones están normalmente en discusión; por ejemplo, parece haber consenso en el hecho de que el derecho a la vida es inviolable en las democracias actuales; empero, en situaciones específicas como el aborto o la eutanasia, el alcance o la concepción misma de este derecho ha suscitado increíbles discrepancias. ${ }^{15}$ Si esto es así, insistiría Waldron, ¿no es inconveniente constitucionalizar dichas condiciones?

\section{La objetividad de los derechos fundamentales (constitucionales)}

La idea de una cultura de los derechos indica la existencia de ciertos derechos morales compartidos en las comunidades existentes, sin embargo, de esto no se sigue una justificación de los derechos constitucionales. Estos derechos se diferencian de los morales en que son posi-

15 El caso de la eutanasia es muy diciente en cuanto a la discusión conceptual acerca de qué se entiende por vida. El comprender la vida solamente desde una perspectiva biológica va a llevar a tomar una posición distinta sobre la eutanasia que si se la concibe también desde su dimensión de dignidad. tivizados a través de cartas constitucionales o leyes fundamentales, las cuales les otorgan una protección frente a la reforma ordinaria por parte de las instituciones legislativas; esto no quiere decir que no puedan ser objeto de reforma, sino que el procedimiento para ello se presenta de forma más estricta y por lo tanto de gran dificultad. No todos los derechos morales pueden llegar a ser derechos constitucionales, solo aquellos que gozan de un carácter fundamental pueden ser objeto de aquella inmunidad.

Robert Alexy define los derechos fundamentales como "posiciones tan importantes que su otorgamiento o no otorgamiento no puede quedar en manos de una simple mayoría parlamentaria" (2014, pág. 396). Existen ciertos derechos morales cuyo contenido es de tal importancia, e incluso constitutivo, para la democracia, que los hace acreedores de una protección constitucional que los sustrae de la decisión de las mayorías. Sin embargo, el mayor grado de importancia de que gozan esos derechos morales supone un problema acerca de la corrección de estas preposiciones normativas, es decir, la justificación de los contenidos de deber ser que contienen esos derechos morales y su carácter fundamental (juicio de valor); ${ }^{16}$ en pocas palabras, la idea de derechos fundamentales supone la pregunta acerca de su objetividad. ${ }^{17}$

16 Es precisamente el problema que plantea la crítica de Waldron: cómo justificar el carácter fundamental de ciertos derechos morales si sobre estos existe desacuerdo.

17 Contrario a posiciones iusnaturalistas como las de John Finnis o Robert Alexy, en este escrito se pretende dar una justificación no metafísica de los derechos fundamentales para la democracia. 
La objetividad de los derechos fundamentales, como lo muestra Alexy (2008), no puede recaer sobre una teoría de la verdad-objetividad como correspondencia. Esta teoría indica que un enunciado solo se puede tener como verdadero u objetivo en cuanto exista el estado de cosas que el mismo expresa, es decir, la objetividad se entiende como la concordancia entre enunciados y hechos (idea que se extrae del positivismo). La verdad-objetividad de los enunciados normativos (como los derechos fundamentales) estaría dada por su justificación discursiva. ${ }^{18} \mathrm{De}$ la misma forma, Rodolfo Arango (2008) sostiene que la concepción de derechos fundamentales, como posiciones normativas con alto grado de importancia,

Presenta una estructura dialógica, discursiva, e implica un juicio valorativo de fundamentalidad que puede justificarse racionalmente bien sea acudiendo a la solidaridad o bien a valores epistémicos compartidos por los operadores del derecho e identificables con aceptabilidad garantizada bajo condiciones ideales ${ }^{19}$ (pág. 37).

De esta forma, se puede entender que la objetividad de los derechos fundamentales para la democracia no se encuentra en un espacio externo (en el cual se verifiquen), sino que se construye de forma racional a través de la argumentación.

18 Esta es una clara referencia a la teoría discursiva de Jürgen Habermas, por la cual la justificación tanto de las preposiciones normativas como de los juicios de valor depende solamente de los argumentos que sostengan su objetividad.

19 Arango menciona que esto es posible desde el "giro copernicano de Kant en ética”, que consistió en entender que la objetividad de la moral no se gana del lado del objeto (dimensión externa) sino del lado del sujeto (dimensión interna).
Así, si se parte de la premisa, como lo hacen Dworkin y Waldron, de que la democracia requiere como principio fundamental la igual consideración y respeto sobre todas las personas, puede decirse que la objetividad de los derechos morales fundamentales (procedimentales y sustantivos) será resultado de un raciocinio que justifique su coherencia con dicho principio. Esto quiere decir que es posible, e incluso necesario, reconocer que los derechos fundamentales para la democracia gozan de una objetividad construida discursivamente, y por lo tanto no están sujetos a un desacuerdo absoluto y permanente. ${ }^{20}$

No se entiende cómo la teoría de Waldron puede reconocer la existencia de derechos fundamentales para la democracia y a su vez sostener que aquellos no gozan de cierta objetividad, por lo cual deben ser objeto de una continua discusión a través del Parlamento. Para afirmar que un derecho es necesario para la democracia debe reconocerse cuál es su contenido (su núcleo sustantivo por lo menos) y la conexión de este con la idea de un régimen democrático; es decir, la relación de recíproca necesidad que reconoce Waldron entre ciertos derechos y la democracia debe suponer una concepción sustantiva de qué es la democracia, una idea de cuál es el contenido de dichos derechos y por qué ese contenido es constitutivo de la misma democracia. Si se afirma, como lo hace el mismo Waldron (1993), que la libertad de expresión

20 Esto tiene relación con la idea de "integridad legislativa" que ha defendido Dworkin (1986, pág. 176), según la cual la actividad legislativa debe estar guiada por aquellos principios objetivos fundamentales, los cuales dan coherencia a todo el derecho en un contexto determinado. 
o el derecho de participación son derechos fundamentales constitutivos de la democracia, se presupone que existe cierta objetividad, por lo menos mínima, sobre el contenido de estos derechos, en caso contrario sería imposible sostener que efectivamente son fundamentales o necesarios.

Una vez se tiene que ciertos derechos morales son objetivos (de acuerdo con una justificación argumentativa que los relaciona con el principio básico de la democracia), la forma más adecuada de protegerlos será a través de cartas constitucionales que los sustraigan del debate de mayorías. Si se quiere tomar en serio la protección de esos derechos objetivos, debe aceptarse la idea de una constitucionalización que los blinde frente a las constantes reformas legislativas. Sin embargo, esto no quiere decir que la constitucionalización de estos derechos fundamentales objetivos suponga eliminar un cierto nivel de desacuerdo sobre el alcance de sus contenidos; de hecho, la práctica constitucional muestra que los foros constitucionales (foros en que se discuten el alcance y el contenido de los derechos constitucionales) se caracterizan por ser espacios de amplia deliberación democrática.

\section{La práctica constitucional como un espacio de deliberación representativa}

La práctica judicial constitucional evidencia cómo los derechos constitucionales están en constante discusión; su interpretación no es pacífica y por lo tanto de forma permanente se están redefiniendo sus contenidos particulares.
El foro constitucional se convierte en un foro de principios, en términos de Dworkin, donde se intenta interpretar las distintas condiciones democráticas a la luz de las diferentes moralidades (críticas o tradicionales, por ejemplo) o ideologías que precisamente constituyen la pluralidad que da pie al desacuerdo. ${ }^{21}$ Hay múltiples ejemplos que dan cuenta de esto: A) la discusión en los tribunales constitucionales sobre la penalización o no de la eutanasia ha conllevado un debate acerca del contenido o significado del derecho constitucional de la vida (si se debe entender solamente desde su dimensión biológica o si debe tener en cuenta la dimensión de vida digna); B) el litigio constitucional sobre la penalización del aborto ha llevado a debatir el alcance del derecho al libre desarrollo de la personalidad, así como su relación con otros derechos constitucionales como la vida y la protección del menor; C) incluso disposiciones constitucionales claras, como la definición por parte de la Constitución colombiana de quiénes forman una familia, han sido puestas a discusión. ${ }^{22}$

De nuevo, lo anterior muestra cómo la constitucionalización de ciertos derechos fundamentales objetivos no implica que sobre su contenido y alcance no se vuelva a debatir. Sin embargo,

21 En este foro no solo confluyen las distintas moralidades con el objetivo de definir los contenidos de las condiciones de democracia, sino que también pretende evaluar la corrección normativa (en el sentido amplio no jurídico) de la legislación ordinaria.

22 A pesar de que la redacción del artículo 42 de la Constitución Política de Colombia parece clara en consagrar que la familia está compuesta por una pareja heterosexual y sus hijo/as, a través de un litigio en el que tomaron parte distintos actores y organizaciones de la sociedad civil y funcionarios públicos, la Corte Constitucional terminó ampliando (a través de una lectura sistemática del texto constitucional) la noción de familia para incluir a las parejas homosexuales. 
Waldron podría refutar, como efectivamente lo hace, que si bien constantemente se discute acerca del contenido de las disposiciones constitucionales, dichas discusiones dan participación solamente a los jueces que deciden al respecto (clásica objeción frente al poder contra mayoritario de los jueces), lo cual ciertamente no corresponde a un régimen democrático. Frente a esto, si bien ha sido amplia la literatura que se ha dedicado a responder a este tipo de críticas (sobre todo la literatura norteamericana), la respuesta que desde la investigación empírica brinda Charles Epp parece ser más persuasiva.

A través de un análisis comparado de las prácticas de activismo judicial en diferentes países (Estados Unidos, India, Gran Bretaña y Canadá), Epp (2013) concluye que a pesar de las disquisiciones teóricas al respecto, la práctica demuestra que los derechos constitucionales en general reposan en una estructura de sostén que tiene una amplia base en la sociedad civil. Según este autor, las discusiones en torno a la interpretación de los contenidos de las disposiciones constitucionales requieren de una presión impulsora externa al sistema judicial proveniente, especialmente, de las organizaciones civiles defensoras de derechos, entre otros agentes. De esta forma se tiene que en los debates sobre los desacuerdos en torno a las disposiciones constitucionales no solo son los jueces los que cuentan con participación, sino que diferentes sujetos y organizaciones de la sociedad civil toman parte, y por lo tanto no puede hablarse de una carencia de participación ciudadana desde el punto de vista democrático. Al respecto, el mismo Epp afirma frente a teorías como la de Waldron:

Al afirmar que los derechos son siempre barreras de pergamino, o que siempre están puestos en piedras, esos análisis comúnmente pierden la oportunidad de explorar las condiciones contingentes que dan forma al desarrollo de los derechos constitucionales y al poder judicial en la práctica. La implicación más importante de mi estudio es que (...) los derechos están condicionados al soporte estructural de la movilización legal. Bajo condiciones en que la estructura [civil] de soporte es profunda y vibrante, la atención judicial a los derechos puede ser constante y vigorosa, bajo condiciones de soporte [civil] es superficial y débil, la atención de los jueces frente a los derechos tiende a ser intermitente e inefectiva (...) Los derechos constitucionales, como garantías legales, y la atención judicial hacia ellos son, entonces, constituidos en cooperación con la sociedad civil (1998, págs. 198-196).

Un caso específico de cómo el litigio sobre derechos constitucionales requiere no solo de la actividad judicial sino también de la participación democrática de la sociedad civil es el de las luchas por los derechos reproductivos de las mujeres en Colombia. Isabel Cristina Jaramillo y Tatiana Alfonso (2008) muestran en su estudio cómo los movimientos feministas y los medios de comunicación pudieron lograr, a través del litigio en el foro constitucional, que la legislación penal sobre aborto fuera suavizada por la Corte Constitucional, después de más de treinta años de esfuerzos infructuosos ante el Congreso de la República. 
De hecho, la práctica constitucional no solo muestra cómo los derechos constitucionales mantienen cierto margen de discusión en la cual toman parte no solo jueces sino muchos sectores de la sociedad civil, sino que también muestra cómo el foro constitucional se convierte en un nuevo escenario de discusión política, donde aquellas minorías que no cuentan con acceso a las instituciones legislativas (precisamente por no contar con el voto mayoritario) encuentran un lugar donde pueden ser escuchadas frente al debate de cuestiones fundamentales de política. Cuando Waldron sostiene que los derechos fundamentales para la democracia deben ser puestos a discusión en el Parlamento, no tiene en cuenta que no todos los sectores de la ciudadanía tienen acceso a dicho escenario; en cambio, el foro constitucional sí parece constituir un escenario de deliberación en donde cualquiera, a través de la argumentación, puede presentar sus opiniones sobre los temas de relevancia política que se deciden. Autores como Joseph Raz (un neopositivista) han expuesto cómo el litigio sobre derechos constitucionales se ha convertido en un escenario de deliberación política incluyente:

La política de los derechos constitucionales brinda a los grupos débiles un fácil acceso a los centros de poder; esto es, grupos con un poder económico insuficiente, o con un prestigio social pequeño, o grupos que, debido a la dispersión geográfica o pobre educación entre otros factores, encuentran una dificultad para tener un impacto en la construcción de coaliciones en la política parlamentaria (...) Los grupos que se organizan para pelear sus casos en la arena de los derechos constitucionales suelen representar personas con ninguna posibilidad de que sus casos sean tratados a través de la política parlamentaria. En este sentido, la política constitucional puede empoderar personas que son de facto privadas de sus derechos (Raz, 1995, pág. 43).

Un ejemplo de esto ha sido la lucha constitucional que han dado distintas organizaciones LGBTI (lesbianas, gays, bisexuales, transgeneristas, intersexuales) alrededor del mundo, quienes por constituir una minoría sin posibilidades de acceso a las instituciones legislativas (por lo menos no en forma de una mayoría que pueda sacar adelante sus proyectos) han tenido que acudir a la deliberación en torno a la interpretación del contenido y alcance de los derechos constitucionales.

De esta forma, la práctica judicial demuestra que constitucionalizar ciertos derechos fundamentales objetivos no implica acabar con cierto nivel de desacuerdo sobre estos y, a su vez, que el foro constitucional no solo está compuesto por los tribunales judiciales sino que constituye un foro abierto de discusión democrática, en donde la participación de la sociedad civil y otras instituciones estatales se torna necesaria. Puede, finalmente, entenderse que el escenario de discusión constitucional termina siendo un segundo canal de acción política democrática paralelo al Parlamento.

\section{CONCLUSIONES}

Como se pudo ver a lo largo del texto, la idea de una democracia constitucional no es tan pa- 
cífica como suele pensarse en las sociedades actuales. La tensión entre el autogobierno democrático y la sustracción de derechos del debate de mayorías parte del supuesto de que el desacuerdo es condición básica de la política y por consiguiente de la democracia.

Esta tensión entre constitucionalismo y democracia constituye el núcleo principal del debate entre Jeremy Waldron y Ronald Dworkin. Contrario a lo que ha afirmado la literatura, ambos autores defienden una concepción sustantiva de la democracia, es decir, que esta no se identifica o se evalúa simplemente por el lado del input (procedimientos de decisión política) sino también por el lado del output (contenido sustantivo de las decisiones que se toman). Así, el core de la discusión entre Waldron y Dworkin es el carácter democrático de las cartas constitucionales, dado que para el primero es inconcebible desde el punto de vista democrático sustraer de las mayorías ciertos derechos morales sobre los cuales existe desacuerdo, mientras que para el segundo el atrincherar esos derechos morales, necesarios para la democracia, en constituciones inmunes a la reforma ordinaria constituye el único modo de tomarse en serio los derechos y por lo tanto la democracia.

Recordar las circunstancias del desacuerdo es una tesis de gran valor por parte de Waldron; sin embargo, llevar al extremo el disenso acerca de unos mínimos constitutivos de la misma democracia parece problemático, más aún cuando al mismo tiempo se defiende la idea de que ciertos derechos son necesarios para la existencia de aquel tipo de régimen político.
En primer lugar, reconocer la existencia de una cultura de los derechos como hecho social compartido en las sociedades actuales permite aceptar la idea de que pueden encontrarse ciertos contenidos normativos de gran importancia sobre los cuales hay un consenso, por lo menos sobre el núcleo sustantivo de estos.

En segundo lugar, la objetividad de esos derechos de gran importancia (fundamentales) estará dada ya no por elementos externos, sino por la justificación argumentativa que esté acorde con los principios democráticos. Esta objetividad construida discursivamente permite extraerlos de los debates de mayorías y darles cierta protección frente a la reforma ordinaria.

Por último, el hecho de que exista una objetividad sobre ciertos derechos fundamentales para la democracia permite constitucionalizarlos, pero esto no quiere decir que sobre los derechos constitucionales no se vuelva a disentir. La práctica jurídica muestra cómo el foro constitucional constituye un escenario alternativo de deliberación democrática donde no solo jueces sino integrantes de la sociedad civil toman parte, y donde incluso aquellos sectores de minorías, quienes no tienen acceso ni representación en las instituciones legislativas, cuentan con una participación igualitaria.

\section{Referencias}

1. Alexy, R. (2008). La teoría consensual de la verdad de Habermas. En R. Alexy, Teoría de la argumentación jurídica (págs. 110142). Madrid: Centro de Estudios Políticos y Constitucionales. 
2. Alexy, R. (2014). Teoría de los derechos fundamentales (Segunda ed.). Madrid: Centro de Estudios Políticos y Constitucionales.

3. Arango, R. (2004). Derechos, constitucionalismo y democracia. Bogotá: Universidad Externado de Colombia.

4. Arango, R. (2008). La objetividad de los derechos fundamentales. En R. Arango, Derechos humanos como límite a la democracia: análisis de la Ley de Justicia y Paz (págs. 2342). Bogotá: Grupo Editorial Norma.

5. Bellamy, R. (2007). Political Constitutionalism: A Republican Defence of the Constitutionality of Democracy. New York: Cambridge University Press.

6. Bobbio, N. (1991). Presente y porvenir de los derechos humanos. En N. Bobbio, El tiempo de los derechos (págs. 63-84). Madrid: Editorial Sistema.

7. Bradley, A. (1998). Constitutional Reform, the Sovereignty of Parliament and Devolution. En A. Bradley, Constitutional Reform in the United Kingdom: Practice and Principles (págs. 33-41). Cambridge: University of Cambridge, Centre for Public Law.

8. Colón Ríos, J. (2012). Weak Constitutionalism: Democratic legitimacy and the question of constituent power. New York: Routledge.

9. Dworkin, R. (1977). Taking Rights Seriously. Cambridge: Harvard University Press.
10. Dworkin, R. (1985). A Matter of Principle. Cambridge: Harvard University Press.

11. Dworkin, R. (1986). Law`s Empire. Cambridge: Harvard University Press.

12. Dworkin, R. (1988). El imperio de la justicia. Barcelona: Gedisa.

13. Dworkin, R. (1989). Liberal Community. California Law Review, 77(3), 479-504.

14. Dworkin, R. (1990a). A Bill of Rights for Britain. London: Chatto and Windus.

15. Dworkin, R. (1990b). Equality, Democracy and Constitution: We the People in Court. Alberta Law Review, 27(2), 324-346.

16. Dworkin, R. (1995). Constitutionalism and Democracy. European Journal of Philosophy, 3(1), 2-11.

17. Dworkin, R. (1996). Fredom's Law. Cambridge: Harvard University Press.

18. Dworkin, R. (2006). Is Democracy Possible Here? New Jersey: Princeton University Press.

19. Dworkin, R. (2011). Justice for Hedgehogs. Cambridge: Harvard University Press.

20.Epp, C. (1998). The Rights Revolution. Lawyers, Activists, and Supreme Courts in Comparactive Perspective. London: The University of Chicago Press. 
21. Epp, C. (2013). La revolución de los derechos. Abogados, activistas y cortes supremas en perspectiva comparada. Buenos Aires: Siglo Veintiuno Editores.

22. Fioravanti, M. (2011). Constitución. De la antigüedad a nuestros días. Madrid: Trotta.

23. Gargarella, R. (2014). La sala de máquinas de la Constitución. Dos siglos de constitucionalismo en América Latina 1810-2010. Madrid: Katz Editores.

24. Gargarella, R. y Courtis, C. (2009). El nuevo constitucionalismo latinoamericano: promesas e interrogantes. Santiago de Chile: Cepal.

25. González Bertomeu, J. F. (2011). Against the Core of the Case. Structuring the Evaluation of Judicial Review. Legal Theory, 17(2), 81118.

26. Habermas, J. (2010). Facticidad y validez. Sobre el derecho y el Estado democrático de derecho en términos de teoría del discurso. Madrid: Trotta.

27. Ely, J. H. (1997). Democracia y desconfianza. Una teoría del control constitucional. Bogotá: Siglo del Hombre Editores.

28. Holmes, S. (1997). Precommitment and the Paradox of Democracy. En J. Elster, \& R. Slagstad, Constitutionalism and Democracy. Studies in Rationality and Social Change (págs. 195-241). Cambridge: Cambridge University Press.
29. Jaramillo, I. C. y Alfonso, T. (2008). Mujeres, cortes y medios: la reforma judicial del aborto. Bogotá: Siglo del Hombre Editores.

30. Madison, J. (2001). El Federalista, X. En J. Madison, El Federalista (Segunda ed., págs. 35-41). México D. F.

31. Rancière, J. (1996). El desacuerdo. Política y filosofía. Buenos Aires: Nueva Visión.

32. Raz, J. (1995). Rights and Politics. Indiana Law Journal, 71(27), 27-44.

33. Salazar Ugarte, P. (2007). La democracia constitucional: Una radiografía teórica. Madrid: S.L. Fondo de Cultura Económica de España.

34. Sandel, M. (2003). La república procedimental y el yo desvinculado. En F. Ovejero, J. L. Martí y R. Gargarella, Nuevas ideas republicanas: autogobierno y libertad (págs. 7593). Barcelona: Paidós.

35. Schneider, C. (2000). The Constitutional Protection of Rights in Dworkin's and Habermas' Theories of Democracy. UCL Jurisprudence Review, 101-121.

36. Sunstein, C. (1997). Constitutions and Democracies: an epilogue. En J. Elster, \& R. Slagstad, Constitutionalism and Democracy. Studies in Rationality and Social Change (págs. 327-357). Cambridge: Cambridge University Press. 
37. Waldron, J. (1993). A Right-Based Critique of Constitutional Rights. Oxford Journal of Legal Studies, (13), 18-51.

38. Waldron, J. (1997). The Constitutional Conception of Democracy. American Political Science Association [APSA].

39. Waldron, J. (1998). Judicial Review and the Conditions of Democracy. The Journal of Political Philosophy, 6(4), 335-355.

40. Waldron, J. (2004). Deliberación, desacuerdo y votación. En R. Slye y H. Hongju Koh, Democracia deliberativa y derechos humanos (págs. 249-269). Barcelona: Gedisa.

41. Waldron, J. (2005a). Derecho y desacuerdos. Madrid: Marcial Pons.
42. Waldron, J. (2005b). Entre los derechos y las cartas de derechos. En J. Waldron, Derecho y desacuerdos (págs. 251-275). Madrid: Marcial Pons.

43. Waldron, J. (2005c). La concepción constitucional de la democracia. En J. Waldron, Derecho y desacuerdos (págs. 337-372). Madrid: Marcial Pons.

44. Waldron, J. (2006). The Core of the Case Against Judicial Review. Yale Law Journal, 115(6), 1346-1406.

45. Waldron, J. (2010). A Majority in the Lifeboat. Boston University Law Review, 90, 10431057.

46. Waldron, J. (2014). Five to Four: Why Do Bare Majorities Rule on Courts? The Yale Law Journal, 123(6), 1692-1730. 